\title{
Iron Recovery from Residue of Lateritic Nickel Leaching Industry
}

\author{
Nur V. Permatasari ${ }^{1 *}$, Hadiyanto ${ }^{2}$, Budi Warsito $^{3}$, Adji Kawigraha ${ }^{4}$, and Nur Ikhwani ${ }^{4}$ \\ ${ }^{1}$ Master Program of Enviromental Science, School of Postgraduate Studies, Diponegoro University, \\ Indonesia. \\ ${ }^{2}$ Departement of Chemical Engineering, Faculty of Technic, Diponegoro University, Indonesia. \\ ${ }^{3}$ Departement of Statistic, Faculty of Science and mathematics, Diponegoro University, Indonesia. \\ ${ }^{4}$ Agency for the Assessment and Application of Technology, Indonesia
}

\begin{abstract}
HPAL (High-Pressure Acid Leaching) is one of the important technologies for extracting nickel and cobalt from nickel laterite ore. In the next few years, some plants using this technology will be operated in Indonesia. The production will be estimated to be 543,000 tons per year by 2025. On the other hand, HPAL will produce more than 26 million tonnes of residue, and it requires good management. The residue utilization for certain industrial raw materials is one of the solutions. To determine the potential utilization residue, the characteristic of the residue must be elaborated through some methods. The characterization is carried out based on mineralogical and chemical properties. The feed used in the HPAL process dominates with magnetite and goethite with $41,15 \% \mathrm{Fe}$ and 1,35 $\% \mathrm{Ni}$ content. The residue of HPAL contains $\mathrm{Fe}$ and significant Sulphur content, silica, aluminium and calcium. The quantity of Sulphur must be decreased by the desulfurization method then followed by the reduction process. The analysis shows that HPAL residue is still required additional processing for reducing the Sulphur content. The residue utilization trial still needs to be done to determine the quality of the iron-making products produced produced.
\end{abstract}

\section{Introduction}

The battery in an electric vehicle is one of the solutions in global warming prevention sourced from the combustion of fossil fuels. Presidential Regulation No. 55 of 2019 concerning the Acceleration of Battery-based Electric Motor Vehicle Programs (Battery Electric Vehicle) has been delivered from participating in decreasing the pollution. Indonesian Government efforts have been realized by identification industry needs for accelerating battery-based electric motor vehicles. One of the important decisions is to build battery raw material processing plants. For that reason, in the next years, Indonesia will have some nickel processing plants involving a high-pressure acid leaching method. These plants produce nickel and cobalt-based products for feeding battery plant manufacturers. The battery itself is used for supporting electric motor vehicles. The use of

* Corresponding author: nvita.permatasari@gmail.com 
nickel in electrical batteries to increase often with the demand needs of electric vehicles. Nickel and cabal are very good components in increasing electrical conductivity [1].

If the battery is a solution to solve the problem of environmental pollution due to fossil fuels, then the principle of clean technology must also be applied in the electric battery process due to the waste products from the HPAL. The waste can be dangerous for the environment due to its corrosive property. Some plants use DSTP (Deep Sea tailing displacement) techniques as a solution to dispose of the waste.

The utilization of waste could be a solution for decreasing the environmental problem. The residue characteristic, which is dominated by iron, could be an advantage as raw material in other industries. This study purposes of recovering HPAL residue as iron raw materials. This study purpose may support the decrease of iron ore import from other countries due to the low quality of local iron ore.

High-pressure acid leaching (HPAL) is one method for recovering nickel and cobalt at a certain temperature using Sulphuric acid. This method can achieve high nickel recovery with low acid consumption compared to atmospheric leaching. The temperature used in the HPAL process is around $250 \mathrm{C}$ with about $4 \mathrm{MPa}$ with the autoclave system.

The problem appears with HPAL residue due to the huge quantity of residue, limited space and high maintenance disposal dam. Some companies dispose of residue into the sea using the DSTP technique (Deep Sea Tailing Process). The technique is chosen because it saves costs compared to the disposal dam technique. The tailings produced by PT Halmahera Persada Legend, which produces dry tailings of 6.1 million tons and slurry with 51.9 million tons, will be pumped into the sea with the DSTP technique.

There were some problems with the disposal technique, either with nickel processing plants or other mineral processing plants. In 2015 in Brazil, the breakdown of the tailings dam has killed more than 250 people [1], and residue from Ramu Nickel Plant has polluted the sea around the plant. Failure to process is due to inadequate facilities, operator capabilities and poor handling facilities [1]. Due to two previous accidents, the use of residue generated by the HPAL process may be the best solution to be realized.

\section{Research Method}

This research is a descriptive study using secondary data obtained from literature review, research reports and journals or research related to the topic discussion. The data collected will be to support the research that will be carried out related to HPAL residue as iron raw materials.

\section{Analysis and Discussion}

\subsection{Characteristic of Limonite}

High-pressure acid leaching usually uses limonite as feed-in nickel laterite processing. The XRD pattern of limonite consists of magnetite, maghemite, goethite, siderite and chrysotile. Nickel limonite that is used by PT Halmahera Persada Legend as feed can be seen in Figure 1 below. 


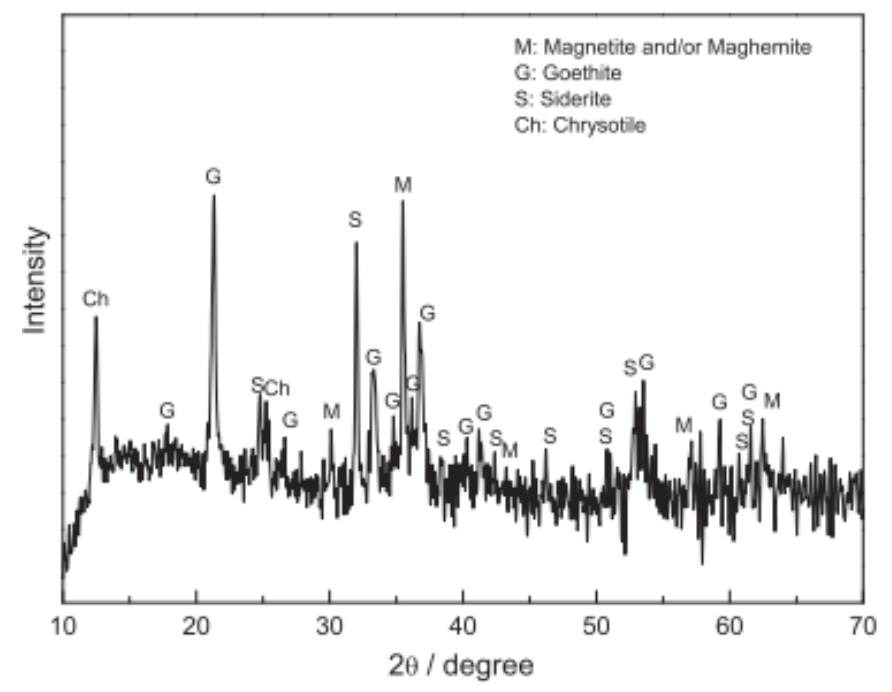

Fig. 1. XRD Pattern Limonite Laterite [2].

The (Error! Reference source not found.) showing XRD pattern limonite laterite there are magnetite, geothite, siderite and chrysolite structure. The mineralogy indicates that the limonite is rich in iron especially in magnetite and goethite [2]. The data (Table 1) is supported with the chemical composition below. Fe content of limonite is $41,15 \%$ and it is followed by silica, alumina, magnesium, nickel and chrome with 15,$22 ; 3,00 ; 1,60 ; 1,35$ and $1,00 \%$.

Table 1. Limonite nickel ore composition (in \%).

\begin{tabular}{|c|c|c|c|c|c|c|c|c|}
\hline Composite & $\mathbf{N i}$ & $\mathbf{C o}$ & $\mathrm{Al}$ & $\mathbf{C r}$ & $\mathbf{C a}$ & $\mathbf{M n}$ & $\mathbf{C u}$ & $\mathbf{F e}$ \\
\hline Limonite & 1.35 & 0.17 & 3.00 & 1.00 & 0.02 & 0.97 & 0.01 & 41.15 \\
\hline Composite & $\mathbf{M g}$ & $\mathrm{SiO}_{2}$ & $\mathrm{~S}$ & $\mathrm{Zn}$ & & & & \\
\cline { 1 - 4 } Limonite & 1.60 & 15.22 & 0.00 & 0.04 & & &
\end{tabular}

The chemical reaction occurs during the pressure acid leaching using 98 weight $\%$ $\mathrm{H}_{2} \mathrm{SO}_{4}$ and at $240-250{ }^{\circ} \mathrm{C}$ is as follow (3)

$$
\begin{aligned}
& \mathrm{NiO}+\mathrm{H}_{2} \mathrm{SO}_{4} \rightarrow \mathrm{NiSO}_{4}+\mathrm{H}_{2} \mathrm{O} \\
& \mathrm{FeOOH}+3 \mathrm{H}^{+} \rightarrow \mathrm{Fe} 3++2 \mathrm{H}_{2} \mathrm{O} \\
& \mathrm{Fe}^{3+}+3 / 2 \mathrm{H}_{2} \mathrm{O} \rightarrow 1 / 2 \mathrm{Fe}_{2} \mathrm{O}_{3}+3 \mathrm{H}^{+}
\end{aligned}
$$

In the autoclave, ion ferric mostly formed into hematite through hydrolysis under a high temperature of more than $200{ }^{\circ} \mathrm{C}$. Sulphuric acid consumed for leaching is generated and can be reused for the next process. Nickel and cobalt extraction from lateritic ore contains around $50 \mathrm{wt} \%$ iron. Pregnant Liquor Solution is rich in nickel and cobalt. Impurities such as iron, magnesium, aluminium have to be removed for increasing the purity of nickel and cobalt. Thus, the removal process is needed through the precipitation method. 


\subsection{Characteristic of residue}

The residue that is generated from high-pressure acid leaching has dominated with iron in the form of $\mathrm{Fe} 2 \mathrm{O} 3$. However, the residue has low $\mathrm{pH}$; thus, it must be neutralized before being disposed of either in the pond. The chemical composition of residue can be seen in (Table 2) below.

Table 2. Main compositions of nickel tailing before neutralization [4].

\begin{tabular}{|c|c|c|c|c|c|c|c|}
\hline Composite & $\mathbf{N i}$ & Co & Al & $\mathrm{Ca}$ & Mn & $\mathbf{C u}$ & $\mathrm{Fe}$ \\
\hline$(\%)$ & 0.114 & 0.014 & 2.97 & 2.86 & 0.76 & 0.002 & 38.6 \\
\hline Composite & Mg & $\mathbf{S}$ & $\mathbf{Z n}$ & $\mathrm{Cr}$ & $\mathrm{SiO2}$ & & \\
\hline$(\%)$ & 0.74 & 5.38 & 0.01 & 0.94 & 6.60 & & \\
\hline
\end{tabular}

The Table 2 show that beside Fe, residue contains significant Sulphur content, silica, aluminium and calcium. Sulphur is important element that must be eliminated for use in iron making feed. Desulfurization of residue must be taken in place for decreasing to below $1 \%$ of Sulphur.

\subsection{Desulfurization}

Roasting is one of the desulfurization methods for removing Sulphur [5]. Roasting has the purpose of removing impurities that exist in concentrates, not only Sulphur but also arsenic, mercury and other elements. However, the process is dangerous due to the gas pollution of SOx [6]. The flotation technique can be used for removing Sulphur or sulphide minerals [7, 8]. The technique has the advantage of flexibility in operation, economy, efficiency and being environmentally friendly $[9,10]$. The Froth Flotation method can be used to separate the desired mineral from unwanted gangue in the ore $[11,12]$.

Froth flotation technique needs chemical reagents called collectors. They are added to the pulp for enhancing the recovery of valuable minerals [13]. Some chemicals such as xanthates, dithiophosphates, and carbamates are the most widely used in the case of sulphide minerals [14]. Xanthate is a collector that has good water solubility and stability in alkaline conditions. $\mathrm{pH}$ control is important for some compounds that can be separated. Alkalinity can be controlled by adding lime, sodium carbonate and sodium carbonate [15]. The application of the desulfurization process with the flotation technique can be seen in Figure 2 below [16].

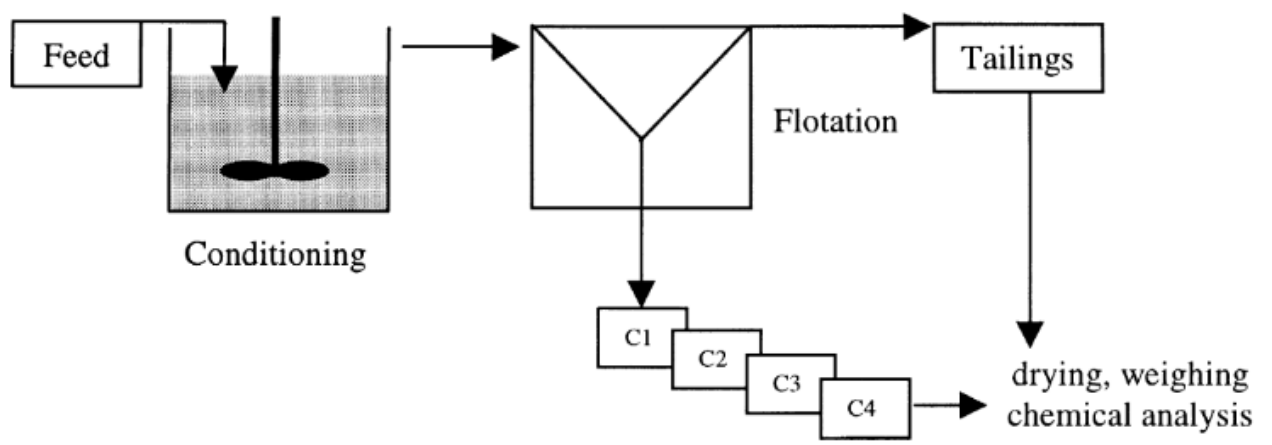


Fig. 2. Flow chart of experimental procedure for the flotation test [16].

The Figure 2 feed will be conditioning and flotation process then process to drying and chemical analysis. Research conducted for Sulphur removal from iron ore tailing found that froth flotation can be combined with gravity and magnetic separation method [17]. The magnetic separation will be separate magnetic material from Sulphur. The effects of various operating parameters such as concentrates of collector, frothier, depressant and activator, $\mathrm{pH}$, solid-in-pulp concentration have been studied on the Sulphur removal using reverse flotation. Optimum process removal Sulphur of parameters at packs 160 grams / t, MIBC dosage 140 grams /t, CuSO4 100 grams /t, airflow rate $101 / \mathrm{min}, \mathrm{pH} 8.5$ and 30\% density pulp.

\subsection{Iron Reduction}

3.5 Usman stated that there are three types of iron ore in Indonesia. They are primary iron ore, iron sand and lateritic iron ore, which consist of 47,144 \%, 47,08\% and 30,26\% iron content [18].

Iron reduction is known as the process for the transformation of iron oxide to iron metal. There are two types of iron reduction processes based on iron reaction with carbon as a redactor. Direct Reduction is a reaction between iron oxide and carbon, whereas indirect reduction is a reaction involving iron oxide and carbon monoxide. Reducing agents such as coke, coal, methane gas is usually used in the iron making industry. The direct and indirect reduction processes will be sponge iron and pig iron, respectively. There are parameters that have to be considered, such as:

\section{a. Temperature}

Temperature is an important parameter in the conversion of iron oxide to iron metal. Boudouard graphic shows that at around $900{ }^{\circ} \mathrm{C}$ to $1000{ }^{\circ} \mathrm{C}$, carbon as the reducing agent will react chemically with oxygen to be carbon monoxide (CO). The latter is an important gas that converts all of the iron oxide forms to other oxide and finally from iron oxide to iron metal. The conversion of $\mathrm{C}$ cannot be achieved below $900{ }^{\circ} \mathrm{C}$. Optimum iron metallization at $1000{ }^{\circ} \mathrm{C}$ is $97,08 \%$ (35). In iron making industry, the operational temperature will in $1000{ }^{\circ} \mathrm{C}$ to $1200 \mathrm{C}$ [19].

b. Time

The direct constant between iron oxides and reducing gas plays an important role in both direct and indirect reduction. The length of time resistance will affect the reduction process and thus increase the product metallization [20]. The graph can be seen (Fig. 1) below. 


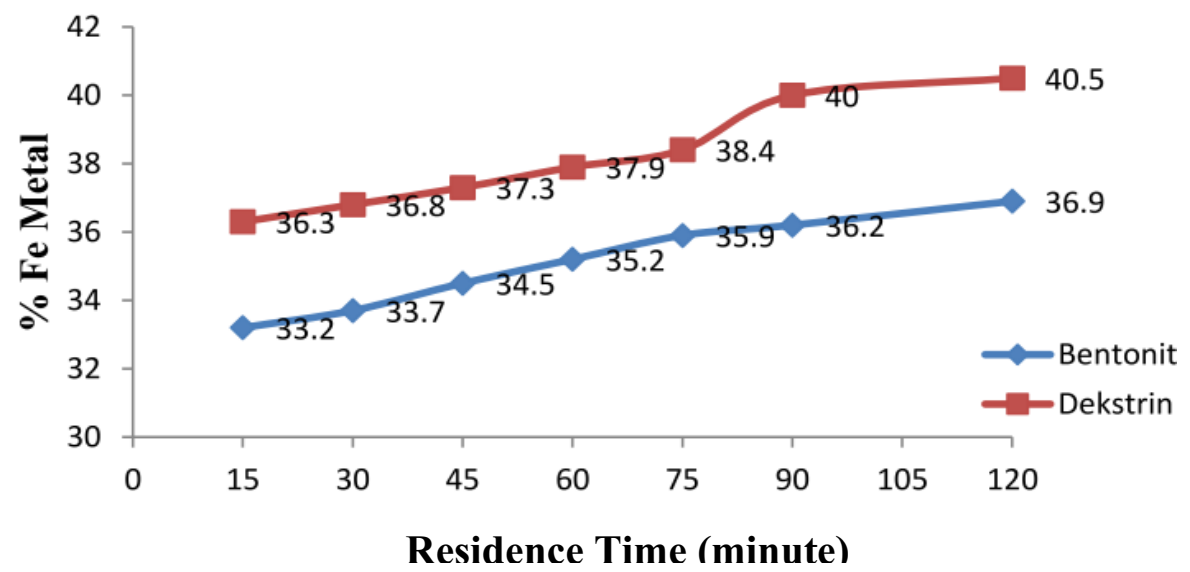

Fig. 1. Effect of holding time at $950{ }^{\circ} \mathrm{C}$ on the increase to $\mathrm{Fe}$.

The graph (Fig. 1) shows the relation between residence time and metallization at 950 ${ }^{\circ} \mathrm{C}$ with bentonite and dextrin as binder. Longer residence time will increase the metallization for both binders.

c. Reducing agent

Reducing agent or redactor is important material in iron making industry as carbon monoxide source. The reaction will be as below:

First step : Hematite reduction

$\begin{array}{ll} & 3 \mathrm{Fe} 2 \mathrm{O} 3(\mathrm{~s})+\mathrm{CO}(\mathrm{g}) \leftrightarrow 2 \mathrm{Fe} 3 \mathrm{O} 4(\mathrm{~s})+\mathrm{CO} 2(\mathrm{~g}) \\ \text { Second step : } & \text { Magnetite reduction } \\ & \mathrm{Fe} 3 \mathrm{O} 4(\mathrm{~s})+\mathrm{CO}(\mathrm{g}) \leftrightarrow 3 \mathrm{FeO}(\mathrm{s})+\mathrm{CO} 2(\mathrm{~g})\end{array}$

Third step : Wustite reduction

$$
\mathrm{FeO}(\mathrm{s})+\mathrm{CO}(\mathrm{g}) \leftrightarrow \mathrm{Fe}(\mathrm{s})+\mathrm{CO} 2(s)
$$

Equation (4) to (5) This shows that Carbon is important in the reduction process. Thus, the quality of the reducing agent is determined by its free carbon content. The term of fixed Carbon in Carbon-based reducing agent show the potential Carbon that can be converted to carbon monoxide gas. Coal and coconut charcoal has around $46 \%$ and $70 \%$, respectively [21].

Another reducing agent used in the iron making industry is hydrogen. They used in iron sand reduction consisting of limonite as equation (7) at $1050^{\circ} \mathrm{C}$.

$$
2 \mathrm{FeTiO} 3(\mathrm{~s})+\mathrm{H} 2(\mathrm{~g}) \leftrightarrow \mathrm{FeTi} 2 \mathrm{O} 4(\mathrm{~s})+\mathrm{Fe}(\mathrm{s})+\mathrm{H} 2 \mathrm{O}(\mathrm{g})
$$

Graph (Fig. 2) below shows the evolution of residual carbon with heating time or residence time. Carbon will decrease with a residence time of iron pellet. 


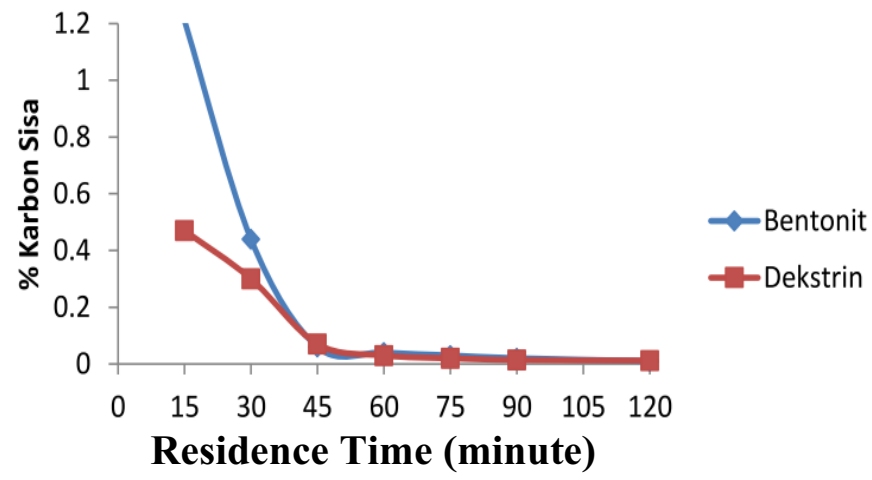

Fig. 2. The graph of the contact between time resistances to the rest of the carbon.

Research shows that a briquette consisting of iron ore mixed with binders such as dolomite and a mixture of redactor powder in a muffle furnace at $1350{ }^{\circ} \mathrm{C}$ for 3 hours will increase the iron content by $64,145 \%$ [22]. The process starts with the DE volatilization of reducing agent at $300{ }^{\circ} \mathrm{C}$ for forming carbon, tar and gas as $\mathrm{CxHy}, \mathrm{H} 2, \mathrm{CO}$ and N2). Carbon monoxide and $\mathrm{H} 2$ reduce iron oxide to iron metal.

d. Limestone

Flux agent such as limestone is used to favourite the formation of slag by decreasing its temperature. The composition of limestone can be seen

Table 3 below.

Table 3. Chemical composition of limestone [21].

\begin{tabular}{|c|c|}
\hline Composition & Grade (\%) \\
\hline $\mathbf{C a O}$ & 53.2 \\
\hline $\mathbf{M g O}$ & 0.28 \\
\hline $\mathrm{SiO2}$ & 0.7 \\
\hline LOI & 41.8 \\
\hline
\end{tabular}

In

Table 3 it is described that Bentonite contains a lot of $\mathrm{CaO}(53.2 \%)$ for help process in reduction.

e. Binder 
Binder is usually added for forming iron ore pellets. Bentonite is one of the binders used in iron making. Bentonite has a chemical composition as below. The addition of bentonite to iron ore is to make a composite consisting of iron ore and carbon-based reducing agent. Moreover, the addition must be calculated for favourite the formation of slag during either the reduction process or smelting. The composition of bentonite can be seen Table 4 below.

Table 4. Main chemical composition of the bentonite (wt\%) [23] .

\begin{tabular}{|c|c|c|c|c|c|c|c|}
\hline $\mathbf{T F e}$ & $\mathrm{AL}_{2} \mathrm{O}_{3}$ & $\mathrm{SiO}_{2}$ & $\mathbf{C a O}$ & $\mathrm{MgO}$ & $\mathrm{MnO}$ & $\mathrm{K}_{2} \mathbf{O}$ & $\mathbf{N a}_{2} \mathbf{O}$ \\
\hline 1.65 & 14.11 & 63.1 & 2.34 & 2.06 & 0.057 & 1.15 & 2.49 \\
\hline
\end{tabular}

In Table 4 the content in the binder includes $\mathrm{Al}_{2} \mathrm{O}_{3}, \mathrm{SiO}_{2}, \mathrm{CaO}, \mathrm{MgO}, \mathrm{K}_{2} \mathrm{O}$ dan $\mathrm{Na}_{2} \mathrm{O}$. Silica Content (63.1\%) dominates the bentonite content.

\section{Conclusion}

Residue from the nickel laterite industry using high-pressure acid leaching can be used as feed for the iron making industry. There are several steps to experiment, including the desulfurization for removing Sulphur content and iron metallurgical test. The iron content of residue must be increased for optimizing the product and decreasing the slag during the iron reduction process. The iron metallurgical test involves temperature, time reducing and binders to optimize the metallization of pellet. The operational temperature used is 1000 $1200{ }^{\circ} \mathrm{C}$, for time reducing is around 2 hours or more and Limestone as redacting agent and can use bentonite binder.

\section{References}

1. S. S. Rahardi, Study on the application of high electrical conductivity materials for improving performance of lithium-ion batteries, 31-42 (2017)

2. B. Wang, Q. Guo, G. Wei, P. Zhang, J. Qu, T. Qi, Hydrometallurgy characterization and atmospheric hydrochloric acid leaching of a limonitic laterite from Indonesia, Hydrometallurgy, 129-130 (2012)

3. K. Shibayama, T. Yokogawa, H. Sato, M. Enomoto, O. Nakai, T. Ito, F. Mizuno, Y. Hattori, Taganito HPAL Plant Project, Miner Eng., 88, 61-5 (2016)

4. T. Gultom, A. Sanipar, High pressure acid leaching : a newly introduced technology in Indonesia, Int Conf Min Enviromental Technol., (2020)

5. V. C. Srivastava, An evaluation of desulfurization technologies for sulfur removal from liquid fuels, Rsc Adv., 2(3), 759-83 (2012)

6. Y. Huang, D. Dang, G. Han, S. Yang, Research on the desulfurization of high sulfur bauxite, In: TMS Annual Meeting \& Exhibition Springer, 181-5 2018

7. A. P. Chandra, A. R. Gerson, A review of the fundamental studies of the copper activation mechanisms for selective fl otation of the sul fi de minerals, sphalerite and pyrite, Adv Colloid Interface Sci., 145(1-2), 97-110 (2009)

8. B. A. Wills, J. A. Finch, Froth flotation, Wills' Miner Process Technol., 7, (2016)

9. R. Prakash, S. K. Majumder, A. Singh, Chemical Engineering \& Processing : Process Intensi fi cation Flotation technique: Its mechanisms and design parameters, 127, 
249-70 (2018)

10. Z. Yin, W. Sun, Y. Hu, C. Zhang, Q. Guan, K. Wu, Evaluation of the possibility of copper recovery from tailings by flotation through bench-scale, commissioning, and industrial tests, J Clean Prod., 171, 1039-48 (2018)

11. S. A. Khoso, M. I. Abro, M. H. Agheem, Mineralogical study of Zard Koh and Kulli Koh iron ore deposits of Pakistan, Mehran Univ Res J Eng Technol., 36(4), 8 (2017)

12. G. P. W. Suyantara, T. Hirajima, H. Miki, K. Sasaki, S. Kuroiwa, Y. Aoki, Effect of $\mathrm{H} 2 \mathrm{O} 2$ and potassium amyl xanthate on separation of enargite and tennantite from chalcopyrite and bornite using flotation, Miner Eng., 152, 106371 (2020)

13. S. Aghazadeh, S. K. Mousavinezhad, M. G'harabaghi, Chemical and colloidal aspects of collectorless fl otation behavior of sul fi de and non-sul fi de minerals. 225, 203-17 (2015)

14. P. P. Manca, G. Massacci, D. Pintus, G. Sogos, The flotation of sphalerite mine tailings as a remediation method, Miner Eng., 165, 106862 (2021)

15. B. A. Wills, J. Finch, Wills' mineral processing technology: an introduction to the practical aspects of ore treatment and mineral recovery, (Butterworth-Heinemann, 2015)

16. M. Benzaazoua, H. Bouzahzah, Y. Taha, L. Kormos, D. Kabombo, F. Lessard, Integrated environmental management of pyrrhotite tailings at Raglan Mine: Part 1 challenges of deSulphurization process and reactivity prediction, 162, 86-95 (2017)

17. F. Nakhaei, M. Irannajad, Sulphur removal of iron ore tailings by flotation, J Dispers Sci Technol., 38(12), 1755-63 (2017)

18. D. N. Usman, The availability of the potential of Indonesian iron ore deposits in supporting the national iron and steel industry, J Tek Pertamb., 1-20 (2015)

19. N. Muzakkii, D. Mughni, F. Abdul, Review the effect of temperature resistant to direct reduction of iron ore. J Tek. ITS, 9(2), (2020)

20. S. Oediyani, E. Firdaus, Effect of time resistance and binder against Cilacap iron sand reduction, Tek J Sains dan Teknol., 14(1), 63 (2018)

21. M. Handayani, S. Oedayani, A. Milandia, The Effect of Temperature and Reduction Type of Acquisition of Percent Metalization Results of Iron Ore Reduction from Kalimantan, J Furn., (2016)

22. F. Abdul, H. Wasik, Analysis of the use of several local charcoal types as reducing in the process of making iron sponges (sponge iron) of iron sand raw materials using direct reduction methods, J IPTEK, 22, 43-50 (2018)

23. G. Li, Z. You, Y. Zhang, M. Rao, P. Wen, Y. Guo, T. Jiang, Synchronous volatilization of $S n, Z n$, and As, and preparation of direct reduction iron (DRI) from a complex iron concentrate via CO reduction, 66(9), 1701-10 (2014) 